\title{
Dialogic reflection for social justice - He Anga Huritao
}

New Zealand Journal of Teachers' Work, Volume 17, Issue 1 \& 2, 38-55, 2020

\author{
TIM GANDER \\ The Mind Lab \\ PHILIPPA WINTLE \\ Albany Senior High School
}

\begin{abstract}
This article conceptualises and presents the authors' framework for critical reflection-on-action. 'He Anga Huritao' (translated as a 'framework for reflection') was developed as part of the dialogic discourse intended to transform how New Zealand beginning teachers reflect on their practice. The framework makes reference to concepts of teacher learning and 'inquiry as stance' by CochranSmith and Lytle (1999) as well as literature pertaining to both critical reflection and education for social justice, placing emphasis on a dialogic approach and the tuakana-teina (or mentor/mentee) relationship. The authors' exposure to how critical reflection was experienced by beginning secondary teachers in low decile settings across New Zealand acted as a catalyst for the development of He Anga Huritao. The article describes He Anga Huritao with individual considerations at each phase of the reflective framework, making reference to beginning teachers' experience of reflection using the framework. He Anga Huritao is an informed approach at rethinking critical reflection and aims to improve the quality of teaching for secondary school learners in inequitable settings.
\end{abstract}

\section{INTRODUCTION}

Titiro whakamuri, kōkiri whakamua

Look back and reflect in order to move forward.

With a little effort, most teachers can likely recall a less than ideal teaching experience from the first years of their practice. In revisiting an episode from this tumultuous chapter, they may consider how their thinking changed because of the event and, inevitably, how they would now do things very differently. In this way, experience and hindsight provide a helpful rear-view mirror through which we can reconsider our actions and viewpoints. Without this perspective however, beginning teachers need concrete tools and sincere professional relationships through which to unpack and review their experiences (Kosnik, 2009). When social and educational contexts, in which social justice is crucial, are added to these needs, the need to review, understand and improve becomes paramount. He Anga Huritao is a framework that scaffolds dialogic reflection for social justice 
in these settings. He Anga Huritao does not necessarily assume transferability to other contexts but contributes to an already rich body of research focused on critical reflection in teaching. It results from analysis of beginning teachers' critical reflections against gaps, opportunities and consensus in literature pertaining to: knowledge creation, education for social justice and critical reflection for the beginning teacher. In this way, He Anga Huritao is the result of a synthesis of findings from empirical experiences, frameworks, and approaches that exist in literature. The intention of the framework is to support beginning teachers to develop agency in incrementally improving their practice over time.

The beginning teachers, whose experiences acted as a catalyst for the development of He Anga Huritao, were enrolled in a tertiary teacher education programme in which a course and professional expectation of deliberate critical reflection existed, in order to improve teaching practice. It was observed in dialogue, primarily following observations, between teacher educators and beginning teachers. Assessment activities showed that, in line with the literature, reflections were at times shallow. Deeper engagement with a process of critical reflection relevant to their contexts may support more intentional and authentic reflection, which in turn could improve their practice. The discussion in this article of these teachers' experience of using He Anga Huritao and the nature of their reflective practice prior to using He Anga Huritao is intentionally and appropriately conservative. Further and more specific empirical research will occur at the next phase of research and be published accordingly. The names and specific experiences of these teachers, their schools and the programme in which these teachers were enrolled, have been generalised in this article in order to protect the identity and reputation of the teachers involved.

\section{LITERATURE}

\section{Critical reflection in teacher education}

Through studies over the past century on reflective thinking and scientific method (Dewey, 1910), learning by doing (Gibbs, 1988a), and reflection in action (Schōn, 1983) there is little doubt that applying a critical approach to practice is beneficial. Before launching into any analysis of literature pertaining to critical reflection however, it is important to consider what makes reflection 'critical' in the first instance. The definition from Mezirow (2000) and Freire's (1970) notion of 'praxis' is relevant in understanding what is implied when 'critical' reflection is discussed in this article. Critical reflection, according to Mezirow (2000), requires the practitioner to become acutely "aware of one's own tacit assumptions and expectations and those of others and assessing their relevance for making an interpretation" (p. 4). In other words, the practitioner must understand their own expectations and assumptions including those unsaid, and those of others. In understanding these, the practitioner must assess the relevance of these assumptions and expectations in order to interpret them. Freire (1970) advocated praxis as a relevant critical approach, stating that "human activity is theory and practice; it is reflection and action. It cannot ... be reduced to either verbalism or activism" (p. 125). Freire's notion of praxis indicates that theory and practice are inextricably linked, and the practitioner must engage with theory and understand this relationship to enable transformation. Praxis thus supports an ongoing interaction between theory and reflection in application towards improvement. This critical approach is further supported in the work of Cochran-Smith and Lytle 
(1999), discussed throughout this article, who propose a concept of knowledge creation that includes a focus on a 'knowledge-of-practice' dimension in teacher learning. Here, professional collaboration is essential in "identifying and critiquing one's own experiences, assumptions and beliefs" (p. 279) in teaching, curriculum, policies and practices in their local schools.

There is ongoing debate regarding the most effective processes that can support teachers to learn how to critically reflect. Original thinking from Dewey supported a methodological and structured approach, which defined clear stages. This approach has been supported by the subsequent models from Kothagen (1985), Gibbs (1988b), Smyth (1993) and Johns (1995). Similarly, in a beginning teacher context, Ryan (2013) advocates for beginning teachers to be scaffolded into reflection, and her studies show that without clear support, reflections are often shallow and avoid deep and transformational thinking, a theme that was observed by teacher educators working with the focus group prior to the implementation of He Anga Huritao. Boud and Walker (1998), however, deplore that reflection can be an exercise in accountability with practitioners following "checklists [in] which students work through in a mechanical fashion" (p. 193). Freire (1998) further supported the view that the process of critical reflection should not adhere to methodological rigour as reflection flows in a "dynamic and dialectical movement between 'doing' and 'reflecting on doing'” (p. 43). This criticism of prescriptive approaches to reflection is echoed by Pultorak, (1993) and Spalding and Wilson (2002) who suggest that having opportunities to reflect, but also being able to do so in a variety of ways has a positive impact on the quality of the reflection of beginning teachers.

There is clearly varied thinking in terms of a rigid framework, versus approaches to critical reflection that are varied and dynamic. There is consensus, however, that through critical reflection teachers are able to self-assess, challenge existing knowledge and biases and build on their knowledge base, addressing gaps in their practice. There is further consensus in literature with regard to the benefit of a dialogic process to the transformation of the teacher, which is discussed in depth in this article. This suggestion has been summarised by Walkington (2005) in a study of 240 pre-service teachers. The findings indicated that a consultative mentoring model drawing from personal and contextual factors empowered beginning teachers to explicitly build upon, as well as challenge existing belief structures.

\section{Critical reflection for social justice}

Educational challenges in New Zealand extend beyond attainment and grades. UNICEF-IRC (2019) recently reported that New Zealand ranks an unsatisfactory 33rd out of 38 countries in the OECD with regard to equitable access to quality education, with secondary education in New Zealand being the most inequitable. These figures are amplified by those concerning reading comprehension. In both overall statistics and the performance gap between males and females, New Zealand takes the penultimate place (UNICEF-IRC, 2019). Becoming critically aware of internal assumptions and expectations is vital for teachers in a country which espouses egalitarian values and bi-cultural partnerships, despite neither of these being reflected in statistics, nor in the education system that is failing Māori and Pasifika learners (McIntosh, 2017). In a recent survey of secondary schools in New Zealand (Bonne \& Macdonald, 
2019), it was highlighted that $80 \%$ of teachers were Pākehā [European], and in addition $90 \%$ of principals were also Pākehā. With the demography of students in low decile settings in New Zealand in mind, it could be assumed that the majority of teachers themselves may therefore have not deeply experienced some of the challenges, circumstances or worldviews that their learners experience. This further illuminates the urgent need for a framework that pushes reflection into the realm where educators are encouraged to challenge normative and hegemonic social structures and practices and the conditioned lenses, likely to be their own, that disadvantage others in order to move forward (Ingram \& Walters, 2013). It is thus important that the beginning teacher has opportunities to activate a social consciousness as "developing and raising preservice teachers' critical consciousness [...] is an essential step to preparing them to work as change agents with an increasingly diverse student population" (Woodrow \& Caruana, 2017, p. 28).

\section{Supporting frameworks of knowledge and practice}

Essential to transforming teaching are the concepts of knowledge and practice as referenced earlier in Freire (1970). These concepts are revised in significant depth in a fundamental framework for understanding teacher learning by Cochran-Smith and Lytle (1999). They articulate their framework through three conceptions: 'knowledge-for-practice', 'knowledge-in-practice' and 'knowledgeof-practice'. These distinctions enable educators to understand the use, application and construction of knowledge with regard to teaching practice and critical reflection, and the importance of the construct of 'inquiry as stance' (Cochran-Smith \& Lytle, 1999), as explained below.

The 'knowledge base' which is often referred to as formal knowledge, or the theory that is used for teachers to improve their teaching, can be found within knowledge-for-practice, which also incorporates pedagogical content knowledge (Schulman, 1987), and is the cornerstone of many teacher education courses. This type of knowledge is likely generated by university-based researchers, can be structured with complex language with a focus on an acquisition of knowledge, and can perpetuate hegemonic academic perspectives. If knowledge-for-practice is related to the theory of education, then knowledge-in-practice is in the realm of the 'art' of teaching, supporting the distinct craft which is synonymous with a practical knowledge that is developed when teachers are in front of learners (Cochran-Smith \& Lytle, 1999). This can often be tacit, challenging to quantify and exclusive to teachers who have had the time and experience to attain mastery of the profession.

Cochran-Smith and Lytle (1999) are clear to establish that there are distinctions between knowledge-for-practice and knowledge-in-practice mainly in that 'for' practice is already well known by outside experts or researchers and can be learnt by teachers to highlight effective teaching. 'In' practice, on the other hand, is known by expert teachers, and the beginning teacher requires support from a more experienced practitioner to be able to articulate this knowledge. When focussing on critical reflection it is unproductive to regard knowledge and practice as two separate elements. Knowledge-for-practice and knowledge-inpractice are both required to support the third conceptualisation of knowledge-ofpractice, although it is important to note that knowledge-of-practice is not a culmination of the aforementioned concepts. Knowledge-of-practice acknowledges that "practice is more than practical, that inquiry is more than an 
artful rendering of teachers' practical knowledge, and that understanding the knowledge needs of teaching means transcending the idea that the formalpractical distinction captures the universe of knowledge types" (Cochran-Smith \& Lytle, 1999, p. 274).

When approaching reflection and transformation in this way it is important to acknowledge what Cochran-Smith and Lytle (1999) describe as 'inquiry as stance.' This relies on a richer conception of knowledge that suggests that practice is practical and a rich conception of learning across the professional life span between cultures and communities, exploring "educational purposes [beyond] those implicit in many widespread school-wide reforms" (Cochran-Smith \& Lytle, 1999, p. 289). Inquiry and reflection thus move from being conscious planned events to a way of being and thinking as a professional. This concept in particular is critical in grounding He Anga Huritao within a holistic, relationship and context specific approach to reflection and transformation, which is ultimately geared towards social justice.

\section{HE ANGA HURITAO - A FRAMEWORK FOR REFLECTION}

Following the analysis of the literature around reflection for teachers, it is clear that there is an opportunity for a guided, though non-dictatorial, reflective framework that espouses consultative mentoring, designed to develop into an inquiry stance and a beginning teacher mindset. The opportunity for an approach of this nature is strengthened in examining inequity in some educational contexts in New Zealand. In understanding these contexts, critical reflection, and subsequent transformation, becomes a vital professional activity to meet the needs of learners, their communities and to support a more equitable experience of education. He Anga Huritao means a framework for reflection on action. It consists of five phases and hopes to provide support to teachers working in diverse settings (Fig. 1, below).

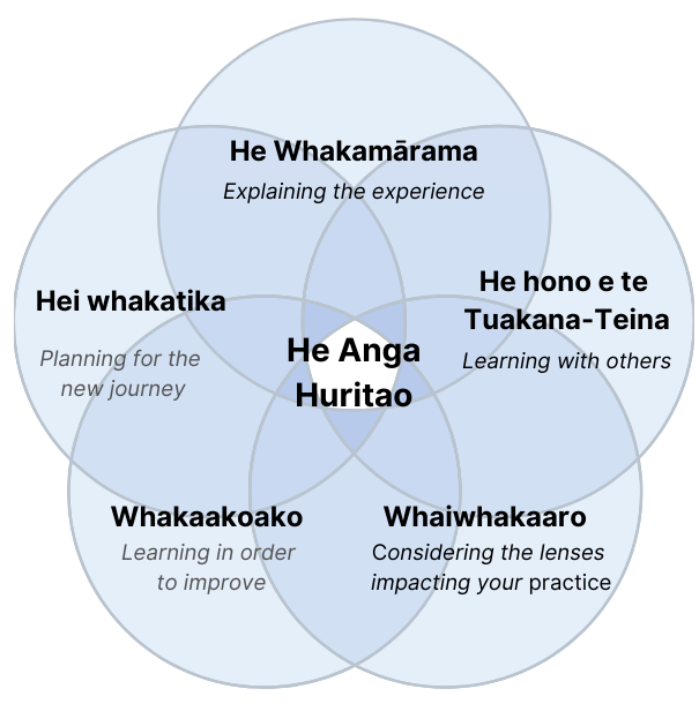

Fig 1: He Anga Huritao 
The phases of He Anga Huritao are:

1. He Whakamārama: Explaining the experience

2. Te hono o te Tuakana-Teina: Learning with others

3. Whaiwhakaaro: Considering the lenses impacting your practice

4. Whakaakoako: Learning in order to improve

5. Hei Whakatika: Planning for the new journey

Within this framework, teachers are encouraged to begin their reflection by revisiting an event and moving through the phases to develop their practice over time. An event can be understood as any stand out phenomena that provides an opportunity for learning, whether that be an event in the classroom, such as an exchange with a student or group of students, a whole class event, or perhaps even in an exchange with a colleague. In He Anga Huritao's application, the focus group tended to reflect on events that were undesirable (for example classroom events where behaviour became challenging to respond to), wanting to understand how and why these occurred with a view to avoid repeat situations. Beginning teachers are invited to move through the different phases in an order that is appropriate to their unique reflective processes. However, they are encouraged to visit each phase with the intention that these practices would become embedded over time.

Before describing He Anga Huritao, it is worth acknowledging that it uses te reo Māori at each phase. It is important to note that whilst the use of te reo Māori is intentional, the framework does not assume cultural locatedness. The authors believe the integrity of the ideas within each phase, and in particular that we learn and grow alongside others and not in isolation, is more adequately represented through te reo Māori. A hope is also that integrating te reo Māori will support a deeper engagement with the phases, be more relevant in a New Zealand setting and that kaiako Māori might be able to access this framework to a greater extent than pre-existing reflective models and frameworks. Also noticeable perhaps is the use of both the past and present tenses in the descriptions of He Anga Huritao henceforth. He Anga Huritao has been described in both the past and present tenses, recognising both the past application of this and the opportunity for future application in relevant contexts. In this way, the article is both a conceptualisation of a reflective approach and a reflection on its application.

\section{Phase 1: He Whakamārama: explaining the experience.}

He Whakamārama is a phase of He Anga Huritao that involves the beginning teacher revisiting an event from their teaching practice to "make explicit, and articulate the tacit knowledge embedded in experience [with the support of] very competent professionals" (Cochran-Smith \& Lytle, 1999, p. 262). Rossiter (2015) highlights that it is complex to re-create an objective reality of an experience, in that it is challenging to situate yourself as an objective observer. Any interpretation of any situation or event will be experienced subjectively, in that we are the subject doing the experiencing. Thus, the expectation of any practitioner to re-create an 'objective' retelling is virtually impossible. It is therefore important in this phase to not expect beginning teachers to somehow 
dilute their retelling of an event to the point of clear objectivity, but instead, in a mentoring capacity support them to step back and, as best they can, outline or narrate the event and contributing factors that occurred. Knowledge-in-practice is scaffolded during this phase of He Anga Huritao through acknowledging that professionals "make new sense of situations by connecting them to previous ones and to a variety of other information" (Cochran-Smith \& Lytle, 1999, p. 263). The following guiding questions were used to support teachers at this stage of their reflective process:

- What, where and when?

- Who did/said what, what did you do/read/see hear?

- In what order did things happen?

- What were the circumstances?

- What were you responsible for?

At the core, the He Whakamarama phase involved the beginning teacher retelling and describing the event using non-judgmental language and creating an honest self-assessment of their role in and experience of the event. This would happen either in a reflective journal, an audio or video recording, or a discussion with a peer or colleague. Clear description of the event or situation provided teachers with a straightforward platform from which their actions could be analysed and further understood, meaning that an action plan following this would be responsive to the issues at play (Gibbs, 1988b).

\section{Phase 2: Te hono o te Tuakana-Teina: Learning from others}

The tuakana-teina phase is one that is centred on more deeply understanding (beyond describing) teaching practice through the act of discussion. Tuakana can be defined as the senior, more experienced critical friend, and teina as the beginning teacher. In this phase of He Anga Huritao, tuakana and teina are required to nurture the dialogic conditions whereby professional transformation can take place. An important limitation to address from the outset is that the extent to which this occurs is likely dependant on the character, biases and openness of both tuakana and teina. These are challenging variables to assess, both in the individual and within established relationships. Therefore it is important that tuakana appreciate their responsibility in not only supporting teina by offering their perspectives and understanding of the event, but also that they themselves critically reflect to better understand the lenses and biases they bring to the relationship and discussion. Also important to note is that this phase in particular should not be limited to a finite period of the reflective process and that tuakana should be sought throughout the reflective process. Here He Anga Huritao becomes an approach for integrated reflective practice and inquiry as stance comes into play.

Whilst knowledge-in-practice brings the previous phase $\mathrm{He}$ Whakamārama into focus, it is more explicitly exposed here through what Cochran-Smith and Lytle (1999) describe as "dyadic situations (as in exchanges between an expert and a less experienced or less expert teacher) sometimes in groups or communities (as in groups of experienced educators) working together to reflect on, inquire about, and transform their experience" (p. 268). Francis 
(1995) makes the case that individual reflection is enriched by group and partner collaborations. A relationship of this nature is often referred to as a 'critical friendship'. At the centre of critical friendship is a habit of engaging in systematic reflection on teaching practices and learning outcomes (Bambino, 2002).

This tuakana-teina phase has benefits for tuakana also as it allows for a reciprocal critical friendship, "a teaching and learning relationship, where the educator [tuakana] is also learning from the student [teina] and where educators' practices are informed by the latest knowledge-for-practice research and are both deliberate and reflective" (Ministry of Education, 2008, p 20). In a reciprocal learning relationship, a mentor and the protégé will be learning from each other as each member of a learning setting brings knowledge with them from which all are able to learn (Keown, Parker, \& Tiakiwai, 2005). Therefore, the Tuakana stage also enables the knowledge-of-practice concept by assuming that "knowledge is socially constructed by teachers who work together and also by teachers and students as they mingle their previous experiences, their prior knowledge, their cultural and linguistic resources, and the textual resources and materials of the classroom" (Cochran-Smith \& Lytle, 1999, p. 280).

Carlson (2019) identifies challenges within critical friendship in addition to those previously mentioned, which include but are not limited to "the facilitation skills of individuals ... and the support or perceived support from [others]" (p. 1). Along these lines, the success of the tuakana-teina phase of the framework rests on three things: the expertise of individuals in enabling the relational conditions whereby teina may reach conclusions about their practice; the support being genuinely beneficial; and the perception that the support is in fact beneficial.

In the Te hono o te Tuakana-Teina phase of He Anga Huritao, beginning teachers as teina were encouraged to analyse ideas and evidence and explore their experience and perceptions more deeply with tuakana of their choice, who had an understanding of the context in which the teacher was operating. This consultative, contextualized tuakana-teina phase of this framework was vital in beginning teachers developing a sense of their assumptions and the relevance of these within a school context. This phase was also vital in beginning teachers learning about what strategies may be appropriate and effective moving forward. Tuakana and teina were encouraged to focus their discussion around:

- Specific teaching behaviours, actions and decisions of the beginning teacher,

- Uncovering and understanding the reasons, assumptions and expectations underpinning the teaching practice of the participant,

- Contextual factors that may have influenced the event,

- Potential strategies moving forward that may be effective in the school context.

Where the beginning teachers were able to form open and trusting relationships with tuakana it was clear that discussion was beneficial. This was evidenced in how beginning teachers analysed the impact of 'new' information such as previously unnoticed or unknown context specific factors that impacted the event being explored, or previously unconsidered perspectives including theoretical perspectives grounded in literature. Whilst there is a tremendous amount to be gained through relationships of this nature, there are clearly 
important considerations, some of which is explored above, that teina, tuakana and those responsible for beginning teacher programmes of mentoring in induction must consider, particularly if the inquiry stance is one that is socially constructed. The social construction element of the inquiry stance is discussed in greater detail below.

\section{Phase 3: Whaiwhakaaro: Considering the lenses impacting your practice}

This phase of reflection is where the 'critical' element of the reflective practice is most visible. Whaiwhakaaro intends to disrupt hegemonic knowledgefor-practice through emphasising a more personalised knowledge-of-practice, supporting the view that "teacher learning hinges on enhancing teachers' understandings of their own actions, their own assumptions, their own reasoning and decisions, and their own inventions of new knowledge to fit unique and shifting classroom situations" (Cochran-Smith \& Lytle, 1999, p. 267). This is the most challenging phase for many beginning teachers as they are faced with the reality and at times irrelevance of the assumptions underlying their decisions with regard to their learners.

Questioning the assumptions on which we act and exploring alternative ideas is not only difficult but also psychologically explosive. "[It] is like laying down charges of psychological dynamite. When these assumptions explode...the whole structure of our assumptive world crumbles. Hence, educators who foster transformative learning are rather like psychological and cultural demolition experts" (Brookfield, 1990, p. 178). Nurturing beginning teachers into a space where this might occur is in many ways an inherently unsafe activity as they are faced with the symbolism of their crumbled assumptive world and deep questions about how to move through the gaping hole this explosion has created. With this in mind, teacher educators and tuakana have a responsibility to nurture the relational conditions whereby beginning teachers may be open to theorizing and constructing their work and connecting it to larger social, cultural, and political issues (Cochran-Smith \& Lytle, 1999, p. 250). The question for professionals working with beginning teachers therefore is how to create the relational conditions, which will be different for each individual teacher, in order to foster trust and transformative learning through reflection. In this way, the considerations in the tuakana-teina phase must run adjacent to these considerations.

The Whaiwhakaaro phase involved deep consideration of the lenses informing the decisions beginning teachers made. Whaiwhakaaro involved acknowledging key assumptions underlying developing practice including questioning how hierarchies (authority, gender, race, class etc.) play out in practice (Smyth, 1993). This examination encouraged engagement with broader historical, social and cultural contexts that influenced the identity of the teacher alongside their teaching practice. It was here where beginning teachers began to take ownership of their development and identified specific areas for learning by considering the relevance of their assumptions and expectations. Some guiding questions that participants were provided with are outlined below. These are adapted from Smyth (1993) and Blake (2015). 
- Whose interests are served by having things this way?

- Why do I teach this way?

- Whose interests are silenced or denied?

- What hierarchies (authority, gender, race, class etc.) exist around me?

- Who makes decisions and who is left out?

- Who benefits and who suffers?

There were clear challenges for beginning teachers in this phase as they developed an inquiry stance, examining dominant assumptions as a professional activity. Indeed this can be equally challenging for the experienced teacher. The deliberate act of casting light on these assumptions was, however, a valuable activity, particularly in those educational settings where the lives, worldviews, cultures and priorities of learners were different to that of the teacher and the teacher was able to safely unearth assumptions about learning that privileged, for example, learners like them. The Whakaakoako phase described below provided a space where the gaps that emerged through Whaiwhakaaro could be redefined as opportunities to learn and transform.

\section{Phase 4: Whakaakoako: Learning in order to improve}

Whakaakoako involves intentional knowledge seeking and active learning. This involves engagement with knowledge-for-practice and engagement with others to construct relevant knowledge for improved practice. To engage with critical theory and literature is to intentionally disturb the status quo with which many beginning teachers may be comfortable due to their established perspective of education. A comfortable route is to either not engage with the evidence at all, or research to confirm biases. This surface approach is noted by Benade (2015) whose critique on teaching as inquiry in New Zealand schools revealed that evidence produced by teachers to justify change in practice is often little more than student test scores or shallow reflections. A superficial scratch into the literature or evidence avoids the critical edge which Freire (1970) insists on for transformation and social change. Duncan-Andrade, Reyes and Morrell (2008) emphasise the importance of critical theory in realising social justice and draw on a range of critical pedagogues to establish that ongoing theoretical analysis and application of the elements influencing practice must be beyond the cause and effect of traditional theory, which is found in knowledge-for-practice.

What matters in this stage, therefore, is that beginning teachers seek literature beyond that which simply affirms their practice, to include literature that also offers alternative viewpoints and challenges users to "consider and reconsider what they know and believe, to consider and reconsider what it means to know or believe something, and then to examine and reinvent ways of teaching that are consistent with their knowledge and beliefs" (Cochran-Smith \& Lytle, 1999 , p. 272). This literature may well be held beyond libraries, encouraging opportunities to explore oral literature which may live within the schools, whanau (families), communities and Marae, or held as sacred by local kaumatua with a deep understanding of contextualised and place-based knowledge. If He Anga Huritao supports the construction of knowledge, observed in knowledge-ofpractice and within the inquiry stance, then it can be said that Whakaakoako is based in constructivist and sociocultural paradigms and encourages the teacher 
to move through and beyond this knowledge to construct their own meaning within their own context.

Whakaakoako represented the ongoing process of independent and reciprocal learning supporting transformation. This phase supported the transformational role of praxis, and the essential need for theory to 'illuminate' practice (Freire, 1970). In this phase, beginning teachers analysed and evaluated contemporary pedagogical theory alongside personal knowledge in order to devise effective strategies to meet the needs of learners. In engaging with learning of this kind, beginning teachers were encouraged to evaluate how their new learning could be applied, by responding to identified gaps in practice in order to promote change. These gaps were identified through the following phases, as well as through this research process itself. Some guiding questions that supported this phase included:

- What are the areas of your practice that you have identified as needing further development?

- What literature, oral and written, is available to you?

- Where is this literature located?

- What features of the literature you have accessed might be effective strategies moving forward?

- What are the alternative or critical interpretations of this literature?

- What is the relevance of these ideas to your learners and key learning communities?

- What does this look like in your practice?

- In what ways are the ideas in literature new or challenging to you?

Seeking the knowledge and evidence to disrupt and reform practice is a step outside of the comfort zone for many educators and a chasmic leap for almost all beginning teachers. In the discussion associated with Whakaakoako, there was often hesitation around what knowledge could be selected, where to find it, how to digest it and how it could 'fit' into practice. These are particularly important considerations with knowledge construction in mind. Accessing knowledge-for-practice in traditional spaces, like library databases, was a fairly straightforward activity. Socially constructing knowledge was and is, however, a much less straightforward process without clear yardsticks against which to measure success. It is not enough to simply expect teachers to generate new understandings with others without clarity on how this is achieved, especially with unseen power-dynamics at play, which may influence the extent to which beginning teachers value their own perspectives, or actively contribute to knowledge creation. It is in this phase, where there is clear opportunity for action research that centres on the factors that support and enable knowledge creation in specific school contexts and communities.

\section{Phase 5: Hei whakatika: Planning for the new journey}

As discussed above, knowledge-in-practice refers to the "process of acting and thinking wisely in the immediacy of classroom life: making split-second decisions, choosing among alternative ways to convey subject matter, interacting 
appropriately with an array of students, and selecting and focusing on particular dimensions of classroom problems" (Cochran-Smith \& Lytle, 1999, p. 266). In this way, knowledge-in-practice can be seen as reflection in action with teachers responding to the unique conditions of their classroom. Putting the spotlight on the importance of real-time teaching practice, however, is not to discredit the importance of planning ahead. Hei whakatika provides an opportunity for teachers to consolidate their reflection, taking stock of their learnings from and with others. This encompasses the contextual knowledge created, as well as the more formal knowledge-for-practice, both of which have been explored in the previous reflective phases.

The Hei Whakatika phase involved considering the journey of the previous steps. The intention in this phase was for the beginning teacher to develop the critical application of theory into habitual practice, leading to transformation and nurturing inquiry as stance as a way of being. The outcome therefore, in line with knowledge-of-practice is to "shape the conceptual and interpretive frameworks teachers develop to make judgments, theorize practice, and connect their efforts to larger intellectual, social, and political issues as well as to the work of other teachers, researchers, and communities" (Cochran-Smith \& Lytle, 1999, p. 273). The previous phases were expected to culminate in these next steps towards a new journey. This final stage supported the design of practical solutions that, in some way, worked towards casting light and action on the bigger, inequitable picture. Through the experiences of working with learners for whom current educational structures are not fit for purpose in the first instance, through context specific mentoring and collaboration, and through research and the challenging of dominant discourses, the hope was that the beginning teacher might identify some practical solutions as to how they might begin to plan to meaningfully contribute to a movement towards social justice for learners. Some questions that beginning teachers were encouraged to consider during Hei whakatika were:

- What are the practical steps I need to take next?

- How will this challenge existing practice?

- With whom do I need to interact to execute these steps?

- What evidence will I have available to me to know if this is making a difference?

- How will I engage with this evidence to ensure growth?

Following this phase teachers presented plans for further study, lesson and unit plans, communication plans, proactive behavioural response plans and classroom design plans. There was not a clear brief that beginning teachers followed, but they were coached by teacher educators as tuakana to present some artefact that outlined clear steps for improved practice, whether that be inside or outside the classroom. Planning the next steps was often a difficult stage for many beginning teachers, particularly without the practical experience of a wide range of actionable strategies, despite the tuakana relationship and investigation into a wider range of written and oral literature. In addition, there were also elements of heightened self-consciousness at this stage in the critical reflections for many Pākehā beginning teachers working in settings that were predominately Māori and Pacific, occasionally stunning beginning teachers into the apathy of doing nothing at all for fear of causing offence. Tolich (2002) writes of 'Pākehā paralysis' to describe a European approach to research, apparent 
when Pākehā are reluctant to engage in action due to fear of 'getting it wrong' or, through the lens of white fragility, are concerned for their own cultural safety. This can in turn apply in a classroom context, particularly when considering the statistics on the dominantly Pākehā population of educators in New Zealand schools. In an attempt to mitigate this, beginning teachers must seek the conditions where they are supported to act upon their reflections, where actions can be affirmed and supported by tuakana and others and understood through an engagement with relevant literature and context specific knowledge. There is also a need for Pākehā teachers to experience discomfort, as they work towards decolonising their thinking and prioritising perspectives and ways of knowing and being that have been historically marginalised.

\section{CONCLUSIONS}

Titiro whakamuri, kōkiri whakamua

Look back and reflect in order to move forward

Undoubtedly, critical reflection plays an integral role in teachers being able to transform to address inequality in New Zealand. Just as teaching practice requires reflection, so too do the nuances of critical reflection itself, and much like teaching, the process of looking under the hood of reflective practice is a complicated business. Despite the complexity of the nature and challenges of teacher learning and critical reflection, at every opportunity the authors' analysis of the application of He Anga Huritao arrived at the conclusion that it is relational conditions that support transformation. This is underpinned by the statement from Cochran-Smith and Lytle (1999) "teachers learn by challenging their own assumptions; identifying salient issues of practice; posing problems; studying their own students, class-rooms, and schools; constructing and reconstructing curriculum; and taking on roles of leadership and activism in efforts to transform classrooms, schools, and societies. Fundamental to this conception of teacher learning is the idea that teachers learn collaboratively, primarily in inquiry communities and/or networks" (p. 278).

Guided by the principles of the whakatauki Titiro whakamuri, kōkiri whakamua; Look back and reflect in order to move forward, the following factors are deserving of greater consideration in future iterations of He Anga Huritao. Of key significance in this context is the necessity for all parties to nurture the relational conditions that enable a dialogic process to support growth and change. There is the requisite for tuakana to be actively involved in critical reflection of their own practice. Beginning teachers must be agentic in the process of critical reflection, not only guiding the process themselves, but also navigating identified challenges outlined in the considerations and seek support and relationships that will nurture and be to their perceived benefit. A further aspect is the importance for teacher educators to balance the guidance and constraints that a reflective framework provides with the fluid evolution of teaching practice into an 'inquiry of stance'. Collectively one has to consider the overall responsibility to identify what knowledge creation looks like within the inquiry of stance and how it is experienced by teachers, so that it can be curated.

Both the research and the experiences of the focus group make clear that the five phases of reflection interact, not necessarily occurring in isolation. Further iterations of reflective frameworks must be explicit in both vehemently 
encouraging the practice of critical reflection, but also acknowledging the unique processes by which people create and apply new meaning, and to support this as a habit of practice, as opposed to a discrete event. With the above considerations in mind, He Anga Huritao may support critical reflection in settings not dissimilar to that of the focus group. New Zealand schools are characterised by both stunning diversity and damning inequity. Teachers need an array of strategies in their kete to respond to learners. He Anga Huitao aims to support the development of teaching in context so that over time teacher practice may be more equitable and movement towards a more socially just education can be felt. 


\section{APPENDIX A. GLOSSARY OF TE REO MĀORI WORDS}

\begin{tabular}{|l|l|}
\hline Te Reo Māori & Translation \\
\hline He Anga Huritao & A framework for reflection or contemplation \\
\hline Kete & A woven basket used to store objects \\
\hline Pākehā & New Zealander of European descent \\
\hline Tuakana-teina & $\begin{array}{l}\text { Relationship between an elder (tuakana) and a younger (teina) } \\
\text { sibling }\end{array}$ \\
\hline Whakaakoako & To teach, learn or in the case of this article to practice. \\
\hline Whaiwhakaaro & $\begin{array}{l}\text { To consider, take into account, think, reflect on, have consideration } \\
\text { for }\end{array}$ \\
\hline Whakamārama & To illuminate, explain, account, clarify, elucidate. \\
\hline Whakatika & To rise up, set out (on a journey). \\
\hline
\end{tabular}

Manuscript Submitted: February 14, 2020

Revised Manuscript submitted: July 09, 2020

Manuscript Accepted: July 17, 2020 


\section{REFERENCES}

Bambino, D. (2002). Redesigning professional development: Critical friends. Educational Leadership, 59(6), 25-27.

Benade, L. (2015). Teaching as Inquiry: Well Intentioned, but Fundamentally Flawed. New Zealand Journal of Educational Studies, 50(1), 107-120. https://doi.org/10.1007/s40841-015-0005-0

Bonne, L., \& Macdonald, J. (2019). Secondary schools in 2018: Findings from the NZCER national survey. Wellington: NZCER Press.

Blake, C. (2015). How to Teach Social Justice in the Classroom. Retrieved April 2, 2019, from https://education.cu-portland.edu/blog/classroomresources/teaching-social-justice/

Boud, D., \& Walker, D. (1998). Promoting reflection in professional courses: The challenge of context. Studies in Higher Education, 23(2), 191-206. https://doi.org/10.1080/03075079812331380384

Brookfield, S. (1990). Using critical incidents to explore learners' assumptions, in J. Mezirow (ed.) Fostering critical reflection in adulthood. Jossey-Bass.

Carlson, J. R. (2019). "How am I going to handle the situation?" The role(s) of reflective practice and critical friend groups in secondary teacher education. International Journal for the Scholarship of Teaching \& Learning, 13(1), 1-20. https://doi.org/10.20429/ijsotl.2019.130112

Cochran-Smith, M., \& Lytle, S. (1999). Relationships of knowledge and practice: Teacher learning in communities. Review of Research in Education, 24, 249-305.

Dewey, J. (1910). How we think. Boston: D.C. Heath \& Co. https://doi.org/10.1037/10903-000

Duncan-Andrade, J.M.R., \& Morrell, E. (2008). The art of critical pedagogy: Possibilities for moving from theory to practice in urban schools. Peter Lang

Francis, D. (1995). The reflective journal: A window to preservice teachers' practical knowledge. Teaching and Teacher Education, 11(3), 229-241. https://doi.org/10.1016/0742-051X(94)00031-Z

Freire, P. (1970). Pedagogy of the oppressed. (1st ed.). Seabury Press. https://doi.org/10.1086/642915

Freire, P. (1998). Pedagogy of freedom: Ethics, democracy and civic courage. Rowman and Little. https://doi.org/10.1111/rsr.13807

Gibbs, G. (1988a) Learning by doing: a guide to teaching and learning methods. FEU.

Gibbs, G. (1988b). Reflective cycle. Academic Liaison, Employability and Skills (ALES), 1-4. https://doi.org/10.1017/CB09781107415324.004

Ingram, I. L., \& Walters, T. S. (2013). A critical reflection model to teach diversity and social justice. Journal of Praxis in Multicultural Education, 2(1), 23-41. https://doi.org/10.9741/2161-2978.1021

Johns, C. (1995). Framing learning through reflection within Carper's Fundamental Ways of Knowing in Nursing. Journal of Advanced Nursing, 22, 226-234. https://doi.org/10.1046/j.1365-2648.1995.22020226.x

Keown, P., Parker, L., \& Tiakiwai, S. (2005). Values in the New Zealand curriculum: A literature review on values in the curriculum. Unpublished 
report prepared for the New Zealand Ministry of Education. www.minedu.govt.nz

Kosnik, C. (2009). Priorities in teacher education the 7 key elements of preservice preparation. Taylor \& Francis.

Korthagen, F. A. J. (1985). Reflective teaching and preservice Teacher education in the Netherlands. Journal of Teacher Education, 36(5), 1115. https://doi.org/10.1177/002248718503600502

Mclntosh, R. (2017). Future directions in New Zealand schooling: The case for transformation, (July). https://trove.nla.gov.au/version/250452859

Mezirow, J. (2000). Learning as transformation: Critical perspectives on a theory in progress. The Jossey-Bass Higher and Adult Education Series. JosseyBass.

Pultorak, E. G. (1993). Facilitating reflective thought in novice teachers. Journal of Teacher Education, 44(4), 288-295. https://doi.org/10.1177/0022487193044004007

Ministry of Education. (2008). Key evidence: And how we must use it improve system performance for Maori Ka Hikitia Managing for Success: Maori Education Strategy 2008-2012. Wellington, New Zealand: Learning Media Ltd.

Rossiter, A. (2005). Discourse analysis in critical social work: From apology to question. Critical Social Work, 6(1), 1-8.

Ryan, M. (2013). The pedagogical balancing act: Teaching reflection in higher education. Teaching in Higher Education, 18(2), 144-155. https://doi.org/10.1080/13562517.2012.694104

Schōn, D. (1983). The reflective practitioner. Temple Smith. https://doi.org/10.4324/9781315237473

Shulman, L. (1987). Knowledge and teaching: Foundations of the new reform. Harvard Educational Review, 57(1), 1-23.

Smyth, J. (1993). Reflective practice in teacher education. Australian Journal of Teacher Education, 18(1). http://dx.doi.org/10.14221/ajte.1993v18n1.2

Spalding, E., \& Wilson, A. (2002). Demystifying reflection: A study of pedagogical strategies that encourage reflective journal writing. Teachers College Record, 104(7), 1393-1421. https://www.tcrecord.org ID Number: 10987.

Tolich, M. (2002). Pākehā "paralysis": Cultural safety for those researching the general population of Aotearoa. Social Policy Journal of New Zealand, 19, 164-178.

UNICEF-IRC (2019), An unfair start: Inequality in children's education in rich countries, Innocenti Report Card, No. 15, UN. https://doi.org/10.18356/cc811669-en.

Walkington, J. (2005). Becoming a teacher: Encouraging development of teacher identity through reflective practice. Asia-Pacific Journal of teacher education, 33(1), 53-64.

Woodrow, K., \& Caruana, V. (2017). Preservice teachers' perspective transformations as social change agents. Journal of Transformative Education, 15(1), 37-58. https://doi.org/10.1177/1541344616655887 


\section{ABOUT THE AUTHOR(S)}

\section{TIM GANDER}

The Mind Lab

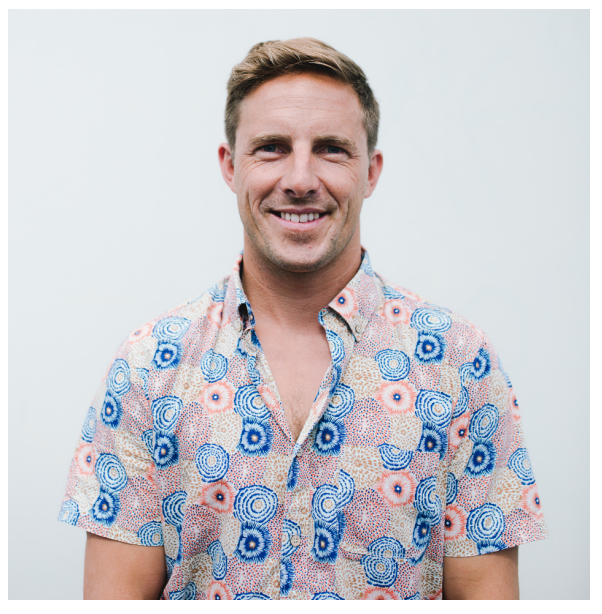

Tim is based in Wainui Beach, Gisborne, and after moving from England spent 10 years teaching in local secondary schools. Tim has a MEd from Massey University focussed on the integration of technology in education, and a current research focus on collaborative synchronous coaching for social justice. Tim has been working for The Mind Lab for six years, for the last three he has had the opportunity to work with a wide range of inspirational educators on the Master of Teaching and Education Leadership programme. tim.gander@themindlab.ac.nz

\section{PHILIPPA WINTLE Albany Senior High School}

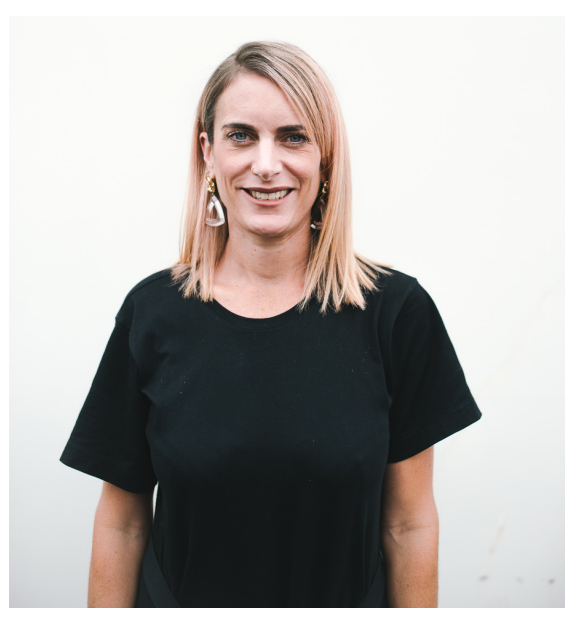

Philippa is the Specialist Subject Leader of English at Albany Senior High School. Previously, she held roles as an Education Director on The Mind Lab's Master of Teaching and Education Leadership. She has experience working closely with and designing programmes of support for beginning teachers. Her interest in critical reflection stems from her work with these teachers and also with experienced teachers as they consider making changes to their practice to meet the needs of learners. pwintle@ashs.school.nz

The opinions expressed are those of the author(s) and not the New Zealand Journal of Teachers' Work. Copyright is held by individual authors but offprints in the published format only may be distributed freely by individuals provided that the source is fully acknowledged. [ISSN-1176-6662] 